REVISTA X, Curitiba, volume 13,n.1,p. 87-110, 2018.

Dossiê Especial: Português como Língua Adicional em contextos de minorias:

(co)construindo sentidos a partir das margens

BIZON \& DINIZ (Orgs.)

\title{
POLÍTICAS LINGUÍSTICAS DE (IN)VISIBILIZAÇÃO DE ESTUDANTES IMIGRANTES E REFUGIADOS NO ENSINO BÁSICO BRASILEIRO ${ }^{1}$
}

\section{Language Policies of (In)Visibilization of Immigrant and Refugee Students in Brazilian Basic Education}

\author{
Leandro Rodrigues Alves DINIZ, Faculdade de Letras - UFMG ${ }^{2}$ \\ Amélia de Oliveira NEVES, UFMG ${ }^{3}$
}

\begin{abstract}
RESUMO: Como reflexo de um cenário internacional de migrações de crise, tem aumentado, no Ensino Básico brasileiro, o número de estudantes estrangeiros (INSTITUTO UNIBANCO, 2018), o que reforça a importância de políticas sensíveis à heterogeneidade linguística. Afiliado à Linguística Aplicada Indisciplinar / Transgressiva (MOITA LOPES, 2006; PENNYCOOK, 2006), este artigo objetiva, justamente, contribuir para o planejamento dessas políticas linguísticas. Para tanto, primeiramente, analisamos alguns elementos de documentos educacionais, argumentando que, no Currículo Básico Comum de Minas Gerais (CBC), o multilinguismo é apagado porque não se fala sobre ele, enquanto, na Base Nacional Comum Curricular (BNCC), ele é silenciado enquanto se fala sobre ele. Posteriormente, defendemos a necessidade de uma "educação linguística ampliada" (CAVALCANTI, 2013), destacando que, a despeito de algumas políticas recentes no campo do chamado Português como Língua de Acolhimento (PLAc) na Educação Básica, a formação de pedagogos e professores ainda é, em geral, marcada pela tradição monolíngue. Além disso, analisamos o funcionamento e alguns efeitos do que temos chamado de "discurso da falta", o qual, no campo do ensino de PLAc, deriva, em grande medida, de um modelo "autônomo" de letramento, criticado por Street (1984; 2013). Concluímos nosso artigo enfatizando a importância de se desnaturalizarem algumas evidências já sedimentadas na área de PLAc, colocando em suspensão seu próprio nome.
\end{abstract}

\footnotetext{
${ }^{1}$ Este artigo avança em algumas discussões realizadas na dissertação de mestrado de Amélia de Oliveira Neves (2018), em eventos científicos (DINIZ, 2018a) e em encontros do Ciclo de Debates em Português como Língua de Acolhimento no Ensino Básico, que temos organizado junto à Secretaria Municipal de Educação de Belo Horizonte, voltados, particularmente, para a formação de profissionais do Ensino Fundamental e Médio (idem, 2018b). O presente texto também retoma discussões feitas nas disciplinas de "Seminário de Tópico Variável em Linguística Aplicada", especificamente, em "Português Língua Adicional: debates contemporâneos", "Políticas linguísticas: a construção das dimensões nacional, oficial e transnacional do português" e "Ensino-aprendizagem de Português como Língua de Acolhimento", oferecidas, respectivamente, em 2016, 2017 e 2018, pelo prof. Leandro Rodrigues Alves Diniz no Programa de Pós-Graduação em Estudos Linguísticos (Poslin) da Universidade Federal de Minas Gerais (UFMG).

${ }^{2}$ Doutor em Linguística. Email: leandroradiniz@gmail.com

${ }^{3}$ Mestranda em Letras (UFMG). Email: ameneves@gmail.com
} 
REVISTA X, Curitiba, volume 13,n.1,p. 87-110, 2018.

\title{
Dossiê Especial: Português como Língua Adicional em contextos de minorias: \\ (co)construindo sentidos a partir das margens \\ BIZON \& DINIZ (Orgs.)
}

PALAVRAS-CHAVE: Português como Língua de Acolhimento; Ensino Básico; Migração de Crise; Multiculturalismo.

\begin{abstract}
As a reflection of an international scenario of crisis migrations, the number of foreign students in Brazilian elementary and high schools has been increasing (INSTITUTO UNIBANCO, 2018), which reinforces the importance of policies sensitive to the linguistic heterogeneity. Affiliated to the Indisciplinary/ Transgressive Applied Linguistics (MOITA LOPES, 2006; PENNYCOOK, 2006), this article aims precisely to contribute to the planning of these language policies. In order to do so, we firstly analyze some elements of educational documents, arguing that in the Basic Common Curriculum of Minas Gerais (CBC) the multilingualism is erased because one does not talk about it, whereas in the National Common Curricular Base (BNCC) it is silenced while one talks about it. Subsequently, we advocate for the need of some "extended linguistic education" (CAVALCANTI, 2013), highlighting that, despite some recent policies in the field of the so-called Portuguese as a Welcoming Language (PWL) in the Basic Education, the development of educational specialists and teachers is still, in general, marked by the monolingual tradition. In addition, we analyze the functioning and some effects of what we have been naming the "discourse of the lack", which, in the field of PWL, derives largely from an "autonomous" literacy model, criticized by Street $(1984 ; 2013)$. We conclude our article emphasizing the importance of denaturalizing some evidence already sedimented in the area of PWL, putting in suspension its own name.
\end{abstract}

KEYWORDS: Portuguese as a Welcoming Language; Basic Education; Crisis Migration, Multiculturalism.

\section{CONSIDERAÇÕES INICIAIS}

Como reflexo do fortalecimento, nos últimos anos, da chamada migração de crise (CLOCHARD, 2007; SANTOS, 2014; LOPEZ, 2016), cresce, em diferentes países, o número de crianças e adolescentes estrangeiros que, muitas vezes, têm baixa proficiência na principal - ou mesmo única - língua de instrução das instituições escolares em que estão - ou deveriam estar - matriculados. Conforme dados do Fundo das Nações Unidades para a Infância (2016), havia 224 milhões de migrantes internacionais no início de 2016, dos quais 31 milhões eram crianças. Sendo o Brasil 
REVISTA X, Curitiba, volume 13,n.1,p. 87-110, 2018.

Dossiê Especial: Português como Língua Adicional em contextos de minorias:

(co)construindo sentidos a partir das margens

BIZON \& DINIZ (Orgs.)

um dos destinos dos deslocados forçados ${ }^{4}$, aumentou, nas escolas de Ensino Básico do país, o número de estudantes cuja primeira língua não é o português. Entre 2008 e 2016, esse aumento foi de $112 \%$, saltando de 34 mil para quase 73 mil, de acordo com dados tabulados pelo Instituto Unibanco (2018) a partir do Censo Escolar de 2016, realizado pelo Instituto Nacional de Estudos e Pesquisas Educacionais Anísio Teixeira (Inep). Desses, 64\% estavam, em 2016, matriculados na rede pública de ensino (ibidem). A figura a seguir traz alguns dados referentes à distribuição de alunos estrangeiros por estado. Como podemos observar, os estados com maior número de matrículas de estrangeiros no país são São Paulo, Paraná e Minas Gerais.

Figura 1: Distribuição do número de matrículas de estudantes estrangeiros por estado.

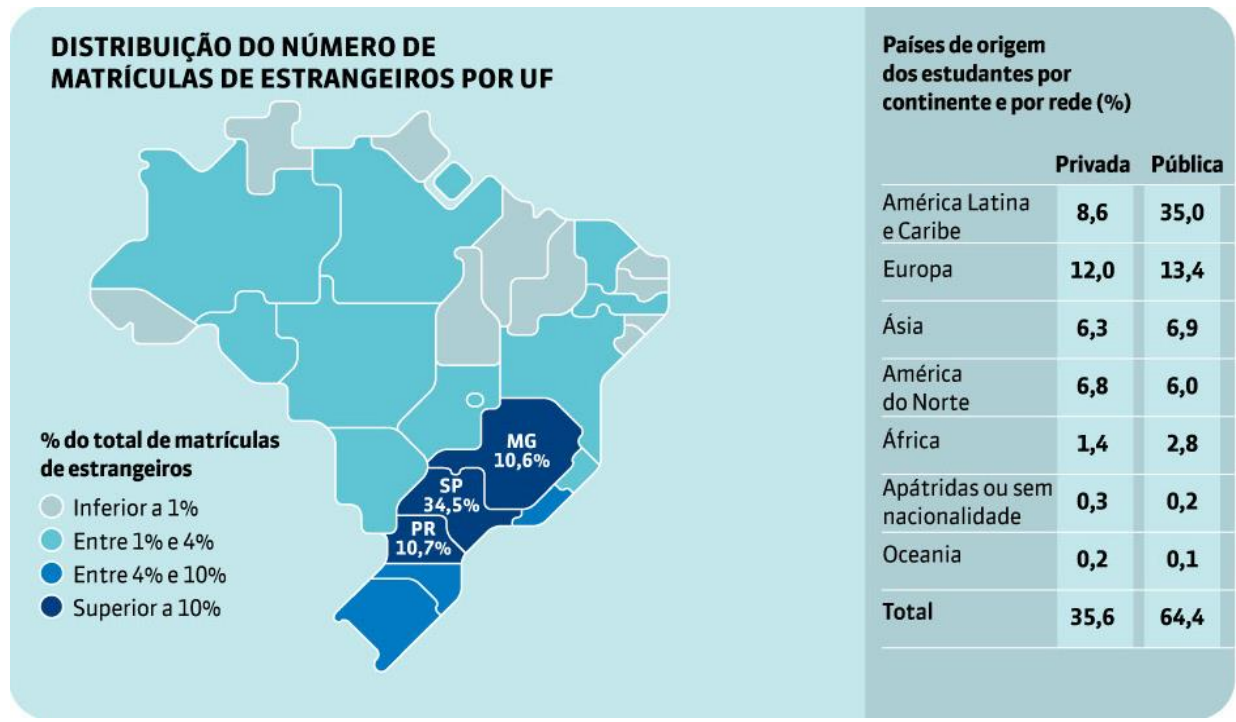

Fonte: Tabulação realizada pelo Instituto Unibanco (2018) a partir de dados do Censo Escolar de 2016, realizado pelo Inep.

\footnotetext{
${ }^{4}$ Segundo dados do Ministério da Justiça (BRASIL, 2018a), dos 10.145 refugiados reconhecidos no Brasil até 2017, 39\% eram de origem síria. Entre 2010 e 2017, 52.243 haitianos e 22.315 venezuelanos solicitaram refúgio no Brasil. A esses dois últimos grupos têm sido concedidos vistos humanitários: apenas 2 nacionais do Haiti e 18 da Venezuela foram reconhecidos pelo governo brasileiro como refugiados. Segundo dados de 2016, o número de haitianos no Brasil é de aproximadamente 85.000 (idem, 2016); o de venezuelanos, em situações migratórias diversas ou em situação irregular, chega a 30.000, considerando dados de julho de 2017 (idem, 2018a). Embora esses números evidenciem que o Brasil tem se firmado como destino de migrantes de crise, é importante ter em vista que, ao contrário de outros momentos de nossa história, a população de estrangeiros no país é proporcionalmente pequena, não passando de 700 mil em um conjunto de mais de 200 milhões de habitantes (CHARLEAUX, 2017). Tal proporção, de $0,35 \%$, é inferior à média dos países em desenvolvimento $(1,7 \%)$ ou de países como os EUA, cuja população é formada por $14,6 \%$ de imigrantes (ibidem).
} 
REVISTA X, Curitiba, volume 13,n.1,p. 87-110, 2018.

Dossiê Especial: Português como Língua Adicional em contextos de minorias:

(co)construindo sentidos a partir das margens

BIZON \& DINIZ (Orgs.)

Os dados disponíveis na Figura 1 apontam para a necessidade imperativa de políticas linguísticas direcionadas a discentes cuja língua materna não é o português 5 . Ainda assim, o português é, em geral, a única língua de instrução para esses alunos, sendo raros, ou inexistentes, os momentos em que esse idioma lhes é ensinado como adicional, o que pode acarretar a produção de casos de "fracasso escolar". Nesse sentido, são preocupantes os dados da Tabela 1 a seguir, que evidenciam a iniquidade no acesso à educação formal quando comparamos a população mundial que está ou não em situação de refúgio:

Tabela 1: Acesso à educação formal por parte da população em situação ou não de refúgio

\begin{tabular}{c|c|c}
\hline & $\begin{array}{c}\text { População em situação de } \\
\text { refúgio (dados referentes a } \\
\mathbf{2 0 1 5}\end{array}$ & $\begin{array}{c}\text { População mundial que } \\
\text { não está em situação de } \\
\text { refúgio (dados } \\
\text { referentes a 2014) }\end{array}$ \\
\hline matriculada no Ensino Fundamental & $50 \%$ & $90 \%$ \\
\hline matriculada no Ensino Médio & $22 \%$ & $84 \%$ \\
\hline matriculada no Ensino Superior & $1 \%$ & $34 \%$ \\
\hline
\end{tabular}

Fonte: Tabela elaborada por Neves (2018) a partir de dados disponibilizados em relatório do Alto Comissariado das Nações Unidas para os Refugiados (2016). Cf.< http://www.unhcr.org/introduction.html> (acesso em: 05 ago. 2018). Os dados da segunda e terceira colunas foram, inicialmente, compilados pelo Instituto de Estatística da Organização das Nações Unidas para a Educação, a Ciência e a Cultura (UNESCO) e pela ACNUR, conforme informações desse relatório.

\footnotetext{
${ }^{5}$ É preciso ter em vista, entretanto, que dados como esses são incipientes para um planejamento de políticas linguísticas para o acolhimento de alunos estrangeiros nas escolas brasileiras. É necessário, por exemplo, saber quais são as línguas maternas desses estudantes, em que línguas adicionais têm proficiência, em que idioma(s) foram alfabetizados, desde quando estão no Brasil, há quanto tempo frequentam a escola brasileira, qual é (ou quais são) a(s) língua(s) utilizada(s) em casa, entre outras informações relevantes. Caso contrário, as políticas serão estruturadas a partir de dois pré-construídos que precisam ser desnaturalizados: (i) o de que todo e qualquer aluno estrangeiro necessita um apoio linguístico específico; (ii) o de que nenhum aluno brasileiro demanda tal apoio. Tais pré-construídos, sustentados na lógica de funcionamento do Estado Nacional Moderno - "um Estado, uma Nação, uma língua" -, apagam a heterogeneidade dos diferentes sujeitos discentes, significando-os a partir de categorias totalizadoras construídas a priori, que estabelecem uma relação unívoca entre a nacionalidade de um aluno e a língua que ele fala.
} 
REVISTA X, Curitiba, volume 13,n.1,p. 87-110, 2018.

Dossiê Especial: Português como Língua Adicional em contextos de minorias:

(co)construindo sentidos a partir das margens

BIZON \& DINIZ (Orgs.)

Além das consideráveis diferenças de acesso à educação formal nos diferentes níveis, a tabela anterior permite perceber que, quanto mais alta a etapa de escolarização, maior a iniquidade entre refugiados e não-refugiados. Entre os fatores que explicam essa discrepância, estão, seguramente, as dificuldades de adaptação à escola do país de refúgio e os consequentes "problemas de aprendizagem", para os quais a baixa proficiência na (principal) língua de instrução desempenha um papel crucial. Embora não tenhamos tido acesso a dados semelhantes para o Brasil especificamente, é provável que desigualdades dessa natureza também ocorram no país ${ }^{6}$, reforçando processos de exclusão não só de refugiados, mas também de imigrantes e de brasileiros que não têm o português como língua materna. De fato, nossas primeiras observações em campo, bem como relatos de profissionais da educação com quem temos conversado ${ }^{7}$, indicam que muitos são os alunos estrangeiros que demonstram dificuldades para realizar ações cotidianas na escola por meio do português ${ }^{8}$. Apesar disso, faltam políticas linguísticas que atendam às necessidades desses estudantes, o que pode favorecer a evasão de discentes que, frequentemente, já apresentam uma série de dificuldades para permanecerem nas escolas.

Comprometidos com a construção de uma agenda de pesquisa para a área de Português como Língua Adicional (PLA) responsiva às demandas da nova ordem mundial e assumindo um compromisso ético com a relevância política do conhecimento que produzimos, filiamo-nos ao referencial da Linguística Aplicada Indisciplinar ou Transgressiva (MOITA LOPES, 2006; PENNYCOOK, 2006). Especificamente, objetivamos, por meio deste texto, trazer subsídios para o delineamento de políticas

\footnotetext{
${ }^{6}$ Daí a importância, por exemplo, de iniciativas específicas para o acolhimento de imigrantes e refugiados no Ensino Superior (cf. LOPEZ; DINIZ, no prelo).

${ }^{7}$ Referimo-nos, particularmente, aos profissionais da Região Metropolitana de Belo Horizonte que têm se preocupado com o desenvolvimento de ações pedagógicas específicas para alunos cuja língua materna não é o português - em particular, imigrantes e refugiados -, com quem temos nos encontrado desde 2017. Em 2018, visando reunir esse público a fim de fortalecer a política linguística de acolhimento a estudantes estrangeiros, demos início ao Ciclo de Debates em Português como Língua de Acolhimento no Ensino Básico, anteriormente mencionado.

${ }^{8}$ Evidentemente, os níveis de proficiência em português dos estudantes que têm outras línguas maternas só podem ser devidamente diagnosticados a partir de instrumentos avaliativos validados. Essa é, certamente, uma ação fundamental para o planejamento de políticas linguísticas para o ensinoaprendizagem de PLAc, que ainda não faz parte da agenda de pesquisas da área.
} 
REVISTA X, Curitiba, volume 13,n.1,p. 87-110, 2018.

Dossiê Especial: Português como Língua Adicional em contextos de minorias:

(co)construindo sentidos a partir das margens

BIZON \& DINIZ (Orgs.)

linguísticas plurais para o ensino-aprendizagem de Português como Língua de Acolhimento (PLAc) no Ensino Básico, em consonância com perspectivas críticas do multiculturalismo (MAHER, 2007a).

Para tanto, focalizaremos, na próxima seção, alguns elementos do Currículo Básico Comum de Minas Gerais e da Base Nacional Comum Curricular, chamando a atenção para processos de (in)visibilização da heterogeneidade linguística. Na seção seguinte, discutiremos em que medida políticas de formação de professores têm sido marcadas pela (in)visibilização de estudantes imigrantes e refugiados, apresentando algumas iniciativas recentes para o ensino de PLAc no Ensino Básico. Subsequentemente, analisaremos o funcionamento e alguns efeitos do que temos chamado de "discurso da falta" na área de PLA, derivado, em grande medida, de um modelo "autônomo" de letramento, criticado por Street $(1984 ; 2013)$. Trata-se de um discurso que, com contornos semelhantes, também significa outros grupos para quem o português é uma língua adicional, como o leitor pode observar em diferentes textos desta coletânea. Encerramos nosso artigo colocando em suspensão a designação "Português como Língua de Acolhimento", como forma de contribuir para a desnaturalização de discursos já bastante sedimentados em uma área que ainda dá seus primeiros passos no Brasil.

\section{A (IN)VISILIBILIZAÇÃO DA HETEROGENEIDADE LINGUÍSTICA EM DOCUMENTOS EDUCACIONAIS}

Não se trata, absolutamente, de uma realidade inédita: desde sempre, escolas de Ensino Básico brasileiras são menos ou mais marcadas pela heterogeneidade, inclusive linguística (MAHER, 2007b), - ainda que hoje essa seja mais evidente, em decorrência da maior presença de estudantes surdos, indígenas, imigrantes e refugiados. Entretanto, documentos educacionais seguem, muitas vezes, reforçando processos de invisibilização dessas vozes do Sul (MOITA LOPES, 2006).

Observemos, em primeiro lugar, o seguinte recorte do Currículo Básico Comum de Minas Gerais (CBC) do Ensino Fundamental - documento publicado em 2008 e 
REVISTA X, Curitiba, volume 13,n.1,p. 87-110, 2018.

\section{Dossiê Especial: Português como Língua Adicional em contextos de minorias: \\ (co)construindo sentidos a partir das margens \\ BIZON \& DINIZ (Orgs.)}

revisado em 2014 -, especificamente, da seção que traz as diretrizes para o ensino de Língua Portuguesa:

É importante ter em mente que o aluno já utiliza a língua portuguesa cotidianamente. Isso significa que ele já domina pelo menos uma das variedades dessa língua e que podemos e devemos partir de seus conhecimentos intuitivos de falante da língua (MINAS GERAIS, 2008, p. 10) [grifos nossos].

De que aluno - no singular - se fala no CBC? Há, claramente, um apagamento dos vários discentes que não "utiliza[m] a língua portuguesa cotidianamente", não "domina[m] uma das variedades dessa língua" e tampouco têm "conhecimentos intuitivos" de tal idioma. Entre eles, encontram-se não apenas parte dos estrangeiros que há muito - e não apenas nos últimos anos, em decorrência do fortalecimento dos processos globais de deslocamento forçado frequentam as escolas mineiras, mas também diversos brasileiros cuja primeira língua não é o português, aí compreendidos muitos indígenas e surdos ${ }^{9}$.

Por outro lado, a polêmica Base Nacional Comum Curricular (BNCC) - homologada para o Ensino Fundamental e Médio em dezembro de 2017 - reconhece a heterogeneidade linguística constitutiva do Brasil. Na seção intitulada "O pacto interfederativo e a implementação da BNCC", destaca-se a importância de "currículos interculturais, diferenciados e bilíngues" e do "ensino da língua indígena como primeira língua" para a Educação Escolar Indígena (BRASIL, 2017a, p 17-18). Já na seção destinada especificamente à Língua Portuguesa, encontramos o seguinte trecho:

Ainda em relação à diversidade cultural, cabe dizer que se estima que mais de 250 línguas são faladas no país - indígenas, de imigração, de sinais,

\footnotetext{
${ }^{9}$ Conforme o Diagnóstico de Migração do Estado de Minas Gerais publicado pelo governo estadual em 2018, calcula-se em 16.550 o número de imigrantes no Estado (disponível em: $<$ https://www.hojeemdia.com.br/primeiro-plano/governo-de-minas-gerais-apresenta-diagn\%C3\%B3sticoin\%C3\%A9dito-para-a-pol\%C3\%ADtica-estadual-de-aten\%C3\%A7\%C3\%A3o-a-migrante-1.611151>.

Acesso em: 03 ago. 2018.). Ainda segundo esse levantamento, os imigrantes provêm, principalmente, do Haiti (11,3\%), Colômbia (8,2\%), Portugal (7,2\%), China (7,1\%) e Itália (7\%), havendo, ademais, 183 refugiados e/ou solicitantes de refúgio, $60,7 \%$ dos quais vêm da Síria. Quanto às comunidades originárias, vivem, em Minas Gerais, mais de dez etnias, com uma grande quantidade de indígenas morando em centros urbanos. Na região metropolitana de Belo Horizonte, estimam-se dois a três mil indígenas (disponível em: 〈http://www.cedefes.org.br/povos-indigenas-destaque/〉. Acesso em: 03 ago. 2018.). Não tivemos acesso ao número de pessoas surdas residentes em Minas Gerais.
} 
REVISTA X, Curitiba, volume 13,n.1,p. 87-110, 2018.

\section{Dossiê Especial: Português como Língua Adicional em contextos de minorias: (co)construindo sentidos a partir das margens BIZON \& DINIZ (Orgs.)}

crioulas e afro-brasileiras, além do português e de suas variedades. Esse patrimônio cultural e linguístico é desconhecido por grande parte da população brasileira.

No Brasil com a Lei $n^{\circ} 10.436$, de 24 de abril de 2002, oficializou-se também a Língua Brasileira de Sinais (Libras), tornando possível, em âmbito nacional, realizar discussões relacionadas à necessidade do respeito às particularidades linguísticas da comunidade surda e do uso dessa língua nos ambientes escolares.

Assim, é relevante no espaço escolar conhecer e valorizar as realidades nacionais e internacionais da diversidade linguística e analisar diferentes situações e atitudes humanas implicadas nos usos linguísticos, como o preconceito linguístico. Por outro lado, existem muitas línguas ameaçadas de extinção no país e no mundo, o que nos chama a atenção para a correlação entre repertórios culturais e linguísticos, pois o desaparecimento de uma língua impacta significativamente a cultura.

Muitos representantes de comunidades de falantes de diferentes línguas, especialistas e pesquisadores vêm demandando o reconhecimento de direitos linguísticos ${ }^{31}$. Por isso, já temos municípios brasileiros que cooficializaram línguas indígenas - tukano, baniwa, nheengatu, akwe xerente, guarani, macuxi - e línguas de migração - talian, pomerano, hunsrickisch -, existem publicações e outras ações expressas nessas línguas (livros, jornais, filmes, peças de teatro, programas de radiodifusão) e programas de educação bilíngue (ibidem, p. 68-69) [grifos nossos] ${ }^{32}$.

As notas de rodapé do recorte acima são as seguintes:

${ }^{31}$ Declaração Universal dos Direitos Linguísticos, Barcelona, 1996, com o patrocínio da UNESCO. Disponível em: 〈http://e-ipol.org/direito-linguistic〉. Acesso em: 6 dez. 2017.

32 O MEC, por meio da Secretaria de Educação Básica, desenvolve o Programa Escolas Interculturais de Fronteira (PEIF), no âmbito do MERCOSUL, em cidades brasileiras da faixa de fronteira e em suas respectivas cidades-gêmeas de países fronteiriços ao Brasil. É objetivo do PEIF promover a integração regional por meio da educação intercultural que garanta formação integral às crianças e aos jovens nas regiões de fronteira do Brasil com outros países, com atenção para os usos linguísticos. Disponível em: 〈http://educacaointegral.mec.gov.br/escolas-de-fronteira>. Acesso em: 6 dez. 2017. Os povos indígenas têm o direito constitucional de desenvolver em seus territórios projetos educacionais e práticas pedagógicas de ensino intercultural e bilíngue. Os pomeranos também dispõem de programas de educação bilíngue, no Espírito Santo. MORELLO, R (Organizadora). Leis e línguas no Brasil. $O$ processo de cooficialização e suas potencialidades. Florianópolis: IPOL, 2015, 140p (ibidem, p. 69) [grifos do original].

Chamamos a atenção, inicialmente, para um efeito de sentido produzido na BNCC: a diversidade linguística seria, antes de tudo, uma realidade "externa" à escola. Observemos, a esse respeito, que, segundo o recorte anterior, "é relevante no espaço 
REVISTA X, Curitiba, volume 13,n.1,p. 87-110, 2018.

\section{Dossiê Especial: Português como Língua Adicional em contextos de minorias:}

(co)construindo sentidos a partir das margens

BIZON \& DINIZ (Orgs.)

escolar conhecer e valorizar as realidades nacionais e internacionais da diversidade linguística" [grifo nosso]. Não se fala, assim, das realidades locais da diversidade linguística, em que diferentes idiomas podem estar presentes, inclusive nas famílias e escolas dos estudantes. Exceção feita à Libras - cujo uso nos espaços escolares é, no trecho anterior, considerado necessário -, outras línguas parecem não fazer parte das instituições escolares "regulares". É como se as línguas indígenas e, sobretudo, as de migração estivessem - ou pudessem estar - presentes apenas nas escolas bilíngues / interculturais. Daí, talvez, o lapso no primeiro parágrafo da seção Língua Portuguesa no Ensino Fundamental - Anos iniciais: práticas de linguagem, objetos de conhecimento e habilidades: "No Ensino Fundamental - Anos Iniciais, aprofundam-se as experiências com a língua oral e escrita já iniciadas na família e na Educação Infantil” (ibidem, p. 87) [grifo nosso]. Em contraposição ao discurso do multilinguismo observado em outros trechos, a designação "a língua oral e escrita", ao retomar, anaforicamente, "língua portuguesa", revela o esquecimento - histórico - dos alunos oriundos de famílias nas quais o português não é utilizado cotidianamente, ou nas quais ele convive com outros idiomas.

Além disso, a BNCC não aponta diretrizes para a valorização do que categoriza como "patrimônio linguístico e cultural", e nem tem em vista as necessidades educacionais específicas dos estudantes de Ensino Básico cuja língua materna não é o português - ainda que tenha sido elaborada em um momento propício para isso, já que questões migratórias estão na agenda do governo ${ }^{10}$. Na apresentação das práticas de linguagem, dos objetos de conhecimento e das habilidades concernentes ao componente curricular de Língua Portuguesa, não há, por exemplo, uma discussão, mesmo que breve, sobre a alfabetização de alunos que têm baixa proficiência em português. Tampouco há, ao que nos consta, movimentos do governo federal para a estruturação de documentos educacionais voltados para esse púbico. É como se o mero "conhecimento"

\footnotetext{
${ }^{10}$ Lembremos que a Lei n. 13.445, que institui a Lei de Migração, foi sancionada em 24 de maio de 2017. Entre os princípios e diretrizes que regem a política migratória brasileira, previstos no artigo $3^{\circ}$, está o "acesso igualitário e livre do migrante a serviços, programas e benefícios sociais, bens públicos, educação, assistência jurídica integral pública, trabalho, moradia, serviço bancário e seguridade social" (BRASIL, 2017b) [grifo nosso].
} 
REVISTA X, Curitiba, volume 13,n.1,p. 87-110, 2018.

Dossiê Especial: Português como Língua Adicional em contextos de minorias:

(co)construindo sentidos a partir das margens

BIZON \& DINIZ (Orgs.)

- ou deveríamos dizer reconhecimento? - da heterogeneidade linguística brasileira e o "respeito às particularidades linguísticas" de grupos monoritarizados na escola representassem, per se, gestos de política linguística capazes de promover a inserção desses discentes na escola ${ }^{11}$.

Reconhecemos, portanto, na BNCC, efeitos do funcionamento de certo discurso contemporâneo sobre o multilinguismo, que se assenta sobre uma "contradição entre seu discurso formal universalizante e sua prática concreta de segregação" (ORLANDI, 2012, p. 7) ${ }^{12}$. Se, no CBC de Minas Gerais, o multilinguismo é apagado por não se falar dele, na BNCC, ele é silenciado enquanto se fala dele. Negam-se, dessa forma, "direitos linguísticos" enquanto se fala do seu reconhecimento, aludindo, explicitamente, à Declaração Universal dos Direitos Linguísticos na $31^{\text {a }}$ nota de rodapé (BRASIL, 2017, p. 69). Com efeito, ainda que se afirme que a BNCC "expressa o compromisso do Estado Brasileiro com a promoção de uma educação integral voltada ao acolhimento,

\footnotetext{
${ }^{11}$ Cumpre observar, ainda, que a Lei n. 9.394, de 1996, a qual estabelece as diretrizes e bases da educação nacional, determinava, no parágrafo $5^{\circ}$ do artigo 26: "Na parte diversificada do currículo será incluído, obrigatoriamente, a partir da quinta série, o ensino de pelo menos uma língua estrangeira moderna, cuja escolha ficará a cargo da comunidade escolar, dentro das possibilidades da instituição" (BRASIL, 1996). Com a entrada em vigor da Lei n. 13.415, de 2017, tal parágrafo foi substituído pelo seguinte: "No currículo do ensino fundamental, a partir do sexto ano, será ofertada a língua inglesa" (idem, 2017c). Dessa forma, antes dessa última lei, a comunidade escolar tinha autonomia para escolher uma língua adicional conforme sua realidade específica. Ainda que, em geral, essa língua fosse o inglês, havia a possibilidade de que, por exemplo, em escolas na fronteira com a Guiana Francesa ou com a Argentina, fosse escolhido o francês ou o espanhol; ou que, em escolas situadas em regiões com grande presença de imigrantes ou indígenas, se optasse por uma língua alóctone ou autóctone importante para as comunidades locais. Atualmente, isso não é mais possível, a não ser que a instituição escolar tenha condições de oferecer, além do inglês, outra(s) língua(s). A lei 13.415 também revogou a de n. 11.161, de 5 de agosto de 2005, a qual determinava que o espanhol deveria ser oferecido obrigatoriamente no Ensino Médio - com matrícula optativa para o aluno - e facultativamente nos currículos plenos do Ensino Fundamental II (idem, 2005). Entre outras consequências dessas mudanças na legislação, está a restrição das possibilidades de que as escolas localizadas em cidades que tem atraído migrantes de crise se organizem a fim de promoverem línguas como o crioulo haitiano, espanhol, árabe e francês - o que poderia ser, inclusive, um elemento central no combate à xenofobia por parte de brasileiros.
}

12 A diversidade também tem passado por um processo de capitalização, sendo frequentemente construída, em termos discursivos, a partir de valores positivos. Entretanto, esse é, muitas vezes, antes de tudo, um recurso de marketing, na medida em que pessoas, instituições e empresas que, supostamente, fazem uma leitura positiva da diversidade assumem posicionamentos em seu dia a dia que, nitidamente, trabalham em favor do monocultural. 
REVISTA X, Curitiba, volume 13,n.1,p. 87-110, 2018.

Dossiê Especial: Português como Língua Adicional em contextos de minorias:

(co)construindo sentidos a partir das margens

BIZON \& DINIZ (Orgs.)

reconhecimento e desenvolvimento pleno de todos os estudantes, com respeito às diferenças e enfrentamento à discriminação e ao preconceito" (ibidem, p. 5) [grifo nosso], mantêm-se, no funcionamento do português como língua nacional, processos de exclusão, inclusive no próprio ensino desse idioma, que continua sendo planejado apenas para aqueles que o têm como língua materna.

Em resumo, o CBC e a BNCC - importantes instrumentos de política linguística de Minas Gerais e do governo federal brasileiro - acabam, cada qual a sua maneira, por obliterar a heterogeneidade linguística constitutiva do Brasil e, consequentemente, diversos discentes matriculados no Ensino Básico, reforçando processos de marginalização. A próxima seção concentra-se em discutir políticas de formação de pedagogos e professores que seguem essa mesma direção ou, ao contrário, trabalham em favor da visibilização de estudantes historicamente apagados nas políticas educacionais e nas políticas linguísticas nelas implicadas.

\section{A (IN)VISILIBILIZAÇÃO DE ESTUDANTES IMIGRANTES E REFUGIADOS NO ENSINO BÁSICO EM POLÍTICAS DE FORMAÇÃO DE PROFESSORES}

A formação de pedagogos e de professores nas diferentes licenciaturas ainda é, em geral, marcada pela tradição monolíngue (CAVALCANTI, 2013) que, conforme argumentamos na seção anterior, embasa os documentos educacionais anteriormente analisados - ainda que travestida sob a roupagem do discurso do multilinguismo no caso da BNCC. Nos próprios currículos dos cursos de Letras, a discussão sobre a heterogeneidade linguística está, em geral, restrita ao que Oliveira (2007, p. 8) denomina "sociolinguística do monoliguismo": uma sociolinguística que se preocupa unicamente com as variáveis e variantes do português.

Mesmo quando graduandos têm a oportunidade de desfazer o mito do monolinguismo brasileiro, raras costumam ser as possibilidades de formação de professores para a atuação em cenários onde mais de uma língua pode estar presente como uma sala de aula de Ensino Básico no Brasil com alunos estrangeiros -, inclusive em universidades localizadas em regiões onde a heterogeneidade linguística salta aos 
REVISTA X, Curitiba, volume 13,n.1,p. 87-110, 2018.

Dossiê Especial: Português como Língua Adicional em contextos de minorias:

(co)construindo sentidos a partir das margens

BIZON \& DINIZ (Orgs.)

olhos, devido a movimentos migratórios, à localização fronteiriça, à presença de comunidades originárias, entre outros fatores. Barbosa (2018), por exemplo, destaca que, apesar do expressivo número de representações diplomáticas sediadas em Brasília e do fortalecimento, nos últimos anos, da presença de discentes estrangeiros nas escolas do $\mathrm{DF}^{13}$, não existe, na capital do país, uma política pública voltada para o acolhimento desses estudantes e para a formação de professores para o trabalho com esse público.

Além disso, são relativamente poucas as universidades brasileiras que formam alunos de Letras na área de $\mathrm{PLA}^{14}$. Não se trata, apenas, de abrir novas perspectivas profissionais para aqueles que podem se interessar pelo trabalho com discentes cuja língua materna não é o português, por exemplo, em Centros Culturais Brasileiros, em escolas de idiomas, em multinacionais ou em ONGs que acolhem imigrantes e refugiados. Trata-se de formar professores de PLA para o próprio Ensino Básico, tendo em vista brasileiros e estrangeiros que não têm o português como língua materna, invisibilizados nos próprios documentos educacionais oficiais, como vimos.

Nos últimos anos, tem sido possível observar, porém, o surgimento de políticas voltadas para o acolhimento de estudantes estrangeiros no Ensino Básico, aí compreendidas aquelas concernentes à formação de professores pré-serviço e em serviço. Sem pretender fazer um levantamento exaustivo dessas iniciativas,

\footnotetext{
${ }^{13}$ Conforme dados fornecidos pela Secretaria de Educação do Distrito Federal (SEC-DF), apresentados pela autora (ibidem), houve, entre 2012 e 2016, 1933 estudantes estrangeiros matriculados no ensino público.
}

${ }^{14}$ A Universidade de Brasília (UnB), a Universidade Federal da Bahia (UFBA), a Universidade Estadual de Campinas (Unicamp) e a Universidade Federal da Integração Latinoamericana (UNILA) são, atualmente, as únicas universidades brasileiras que oferecem licenciaturas em PLA. A licenciatura em Letras - Português do Brasil como segunda língua da UnB, criada em 1998, forma "interessados pelo ensino da língua portuguesa para falantes e usuários de outras línguas, seja língua estrangeira, língua indígena ou língua de sinais" (cf. http://www.lip.unb.br/graduacao/cursos). A licenciatura em Letras Vernáculas - Português Língua Estrangeira da UFBA foi a segunda iniciativa dessa natureza no país, abrindo turmas desde 2006 (cf. https://colegiadosdeletras.ufba.br/402). Na UNILA, foi aberto, em 2015, a licenciatura em Letras - Espanhol e Português como Línguas Estrangeiras (cf. https://www.unila.edu.br/cursos/letras-espanhol-e-portugues). Por fim, o curso de Letras da Unicamp oferece, desde 2017, a habilitação em Português como Segunda Língua / Língua Estrangeira (cf. https://www.iel.unicamp.br/br/content/licenciatura-em-letras-diurno-0). Acesso em: 05 ago. 2018. Outras instituições de ensino superior (IES) oferecem disciplinas no curso de Letras - em geral, optativas voltadas para a formação de professores de PLA. Centros de línguas e projetos de extensão das IES também têm, frequentemente, um papel importante na formação desses profissionais. 
REVISTA X, Curitiba, volume 13,n.1,p. 87-110, 2018.

Dossiê Especial: Português como Língua Adicional em contextos de minorias:

(co)construindo sentidos a partir das margens

BIZON \& DINIZ (Orgs.)

apresentaremos aqui, brevemente, três delas, desenvolvidas em São Paulo, Curitiba e Belo Horizonte.

Na cidade de São Paulo, a partir de uma parceria entre a Secretaria Municipal de Direitos Humanos e Cidadania (SMDHC) e a Secretaria Municipal de Educação (SME), foi criado um projeto pioneiro, denominado Portas Abertas: Português para Imigrantes, cujo objetivo é "estabelecer e garantir o ensino de português para imigrantes de forma gratuita, contínua e capilarizada, dentro da estrutura física e por meio dos recursos humanos da Rede Municipal de Ensino" (SÃO PAULO, 2017a). Conforme a portaria que institui o programa, tais cursos são ministrados por professores efetivos da Rede Municipal - preferencialmente, de Português no Ensino Fundamental II e Médio , que deverão, obrigatoriamente, ter concluído o curso específico sobre o ensino de português para imigrantes oferecido pela SME e pela SMDHC (idem, 2017b). A capacitação dos professores e a elaboração dos materiais didáticos ${ }^{15}$ são apoiadas pelo Centro de Línguas da Faculdade de Filosofia, Letras e Ciências Humanas (FFLCH) da Universidade de São Paulo (USP).

Em Curitiba, em abril e maio de 2018, um curso sobre PLAc, com 80h/aula presenciais, foi oferecido a professores da Rede Pública Estadual de Educação do Paraná (cf. RUANO; OLMO; ALMEIDA, no prelo). Os docentes responsáveis pela oferta do curso - alguns dos quais formados pela Universidade Federal do Paraná (UFPR) - foram selecionados por meio do edital de credenciamento n. 44/2017 da Secretaria de Estado da Educação do Paraná (PARANÁ, 2017).

Já em Belo Horizonte, por meio de uma pareceria entre o Núcleo de Línguas Estrangeiras da Secretaria Municipal de Educação e a Faculdade de Letras (FALE) da UFMG estabelecida em janeiro de 2018, graduandos em Letras têm ministrado, no contraturno, aulas de PLAc para crianças e adolescentes estrangeiros matriculados em escolas de Ensino Básico. Além disso, encontros com professores e outros profissionais da educação da Região Metropolitana de Belo Horizonte têm sido organizados no

\footnotetext{
${ }^{15}$ Cf. o livro didático produzido no projeto (REINOLDES; MANDALÁ; AMADO, 2017).
} 
REVISTA X, Curitiba, volume 13,n.1,p. 87-110, 2018.

\section{Dossiê Especial: Português como Língua Adicional em contextos de minorias:}

(co)construindo sentidos a partir das margens

BIZON \& DINIZ (Orgs.)

âmbito do Ciclo de Debates em Português como Língua de Acolhimento no Ensino Básico (cf. DINIZ; MIRANDA, 2018).

É fundamental que políticas como essas ganhem força nas IES do país. Dados do Observatório das Migrações em São Paulo evidenciam um processo de capilarização das migrações internacionais no Brasil: dos 5.570 municípios brasileiros, 3.432 registraram pelo menos um imigrante internacional entre 2010 e 2015 (BOHEM, 2018). É enganoso, portanto, pensar que apenas instituições localizadas nas metrópoles devem formar professores para o trabalho com PLAc no Ensino Básico. O Brasil necessita de uma política federal para a formação de professores de PLA, para o trabalho com estrangeiros e brasileiros que não têm o português como língua materna, seja nas escolas de Ensino Básico, seja em outros contextos.

Para além de uma formação tecnicista - pautada meramente em discussões sobre abordagens, métodos e técnicas no ensino de línguas adicionais -, destacamos a necessidade de uma educação linguística ampliada,

sofisticadamente inter- e transdisciplinar, socialmente engajada, antropologicamente antenada, plural em seu foco, para incluir os estudos de letramento, os estudos sobre multilinguismo com as questões de intercompreensão e de práticas translíngues, os estudos sobre multiculturalismo (CALVANCATI, 2013, p. 226)

Essa formação é fundamental para se afastar de discursos preconceituosos que atravessam nossas práticas docentes, um dos quais focalizaremos na próxima seção.

\section{O FUNCIONAMENTO DO DISCURSO DA FALTA}

Assim como outros grupos minoritarizados, imigrantes e refugiados no Brasil vêm sendo, frequentemente, marcados por aquilo que temos denominado "discurso da falta". Trata-se de um discurso essencialista e totalizador que, a partir de uma posição etnocêntrica, significa certos sujeitos por aquilo que supostamente "não são", "não fazem”, "não sabem” e "não conhecem”, apagando, consequentemente, suas vivências, suas agências, seus saberes e seus conhecimentos - que, cabe ressaltar, não integram os 
REVISTA X, Curitiba, volume 13,n.1,p. 87-110, 2018.

\section{Dossiê Especial: Português como Língua Adicional em contextos de minorias:}

(co)construindo sentidos a partir das margens

BIZON \& DINIZ (Orgs.)

repertórios daqueles que os enxergam como um conjunto de lacunas a serem preenchidas. Como efeito desse discurso, naturaliza-se a ideia de que tais sujeitos não estão "prontos" para ocuparem os lugares que estão ocupando ou desejam ocupar. No caso específico do ensino de PLAc para grupos minoritarizados, muitas vezes, encontrase naturalizado, por exemplo, o imaginário de que o acesso a certas práticas letradas em português garantirá o acesso a posições sociais mais valorizadas socialmente, quando, na realidade, essa não é uma condição necessária, e nem suficiente ${ }^{16}$.

No campo do ensino de línguas, o discurso da falta deriva, em grande medida, de um modelo "autônomo" de letramento, fortemente criticado por Street $(1984 ; 2013)$. Tal modelo, conforme o autor (2013), se sustenta no princípio de que o letramento, por si só, permitiria a crianças, jovens e adultos “iletrados" desenvolver-se cognitiva, econômica e socialmente, tornando-se cidadãos melhores. Centrado nas habilidades cognitivas dos sujeitos ao se relacionarem com textos escritos - e apenas escritos -, o modelo "autônomo" acaba por apagar as condições sócio-econômicas que respondem pelo suposto "iletrismo" de alguns. Além disso, oblitera uma série de práticas letradas, não reconhecidas enquanto tais a partir de uma posição etnocêntrica. Em oposição a esse modelo, Street (ibidem) argumenta em favor de um modelo "ideológico", o qual considera o letramento como uma prática social, sócio-culturalmente situada. Nessa segunda perspectiva, o letramento varia conforme o contexto e a cultura, de forma que os efeitos de diferentes letramentos também variam segundo as condições específicas.

Decisões recentes sobre usos do Certificado de Proficiência em Língua Portuguesa para Estrangeiros (Celpe-Bras) evidenciam alguns efeitos, na área de PLA, de uma certa hegemonia da concepção autônoma de letramento. A partir do Decreto n. 7498, de 2013, estabeleceu-se que todos os candidatos ao Programa de EstudantesConvênio de Graduação (PEC-G) - inclusive os oriundos da Comunidade dos Países de Língua Portuguesa (CPLP) - deveriam realizar o exame (BRASIL, 2013). Tal exigência é, a nosso ver, "politicamente equivocada, por colocar o Brasil no centro de uma

\footnotetext{
${ }^{16}$ Lopez (2016) mostra os efeitos desse discurso nas falas de profissionais que coordenam ou ministram cursos PLAc, bem como nas de estudantes desses cursos. Cf. também, artigo da autora no presente dossiê.
} 
REVISTA X, Curitiba, volume 13,n.1,p. 87-110, 2018.

\section{Dossiê Especial: Português como Língua Adicional em contextos de minorias:}

(co)construindo sentidos a partir das margens

BIZON \& DINIZ (Orgs.)

'lusofonia', significando as diferenças negativamente, em favor de um português brasileiro capitalizado" (DINIZ; BIZON, 2015, p. 155).

Outro gesto de política linguística que também evidencia os efeitos de um modelo "autônomo" de letramento se deu por meio da publicação da Portaria Interministerial n. 11, de 03 de maio de 2018, cujo artigo $5^{\circ}$ exige, para fins de naturalização ordinária, "a comprovação da capacidade de se comunicar em língua portuguesa" por meio do Celpe-Bras (BRASIL, 2018b). Ora, um elemento-chave na avaliação de proficiência feita nesse exame é a escrita de textos de determinados gêneros, que se atualizam em práticas sociais específicas. Por isso, pode-se considerar que, tal como no modelo "autônomo" de letramento, o Celpe-Bras passa, a partir da exigência estabelecida na portaria em questão, a ser utilizado para a avaliação de usos da escrita em práticas sociais como se esses usos fossem "neutros" e universais no Brasil - e, consequentemente, relevantes para toda e qualquer pessoa que deseje adquirir a nacionalidade brasileira. Novamente, percebemos, portanto, o funcionamento da ideologia monolíngue vigente no Estado brasileiro, a despeito da heterogeneidade linguística constitutiva do país. Para naturalizar-se brasileiro, é preciso saber a língua nacional, independentemente de quem seja o sujeito e de quais usos ele faça do português, na relação com outra(s) língua(s) que integra(m) suas construções identitárias. Em outras palavras, ser aprovado no exame funciona como uma garantia de "letramento" em português, algo considerado fundamental para um "verdadeiro cidadão", digno de adquirir a nacionalidade brasileira.

Especificamente no ensino de PLA, tem nos chamado a atenção a recorrência de afirmações como "Os africanos têm muitos problemas de letramento" e "Os haitianos têm um baixo nível de letramento". Referir-se aos supostamente baixos "níveis de letramento" de certos discentes estrangeiros já se tornou um lugar comum na área, inclusive nas falas de professores claramente engajados na construção de políticas linguísticas de acolhimento a imigrantes, refugiados e estudantes do PEC-G. Tais falas são reveladoras de uma perspectiva "autônoma" de letramento, que, significando os alunos pelas habilidades cognitivas relativas ao uso da escrita que não teriam segundo a 
REVISTA X, Curitiba, volume 13,n.1,p. 87-110, 2018.

Dossiê Especial: Português como Língua Adicional em contextos de minorias:

(co)construindo sentidos a partir das margens

BIZON \& DINIZ (Orgs.)

posição do(a) professor(a), apaga outras práticas de letramento com as quais o(a) próprio(a) docente, muitas vezes, não tem familiaridade.

No funcionamento do discurso da falta, não há espaço para se levantar a possibilidade de que nossas práticas de ensino e avaliação vão ao encontro daquelas com que estão acostumados discentes de determinadas culturas, mas não de outras, o que poderia explicar algumas diferenças de rendimento eventualmente observáveis entre estudantes de diferentes origens ${ }^{17}$. Em nome do "respeito às singularidades" de estudantes de grupos minoritarizados, tendo em vista seus "déficits de letramento", docentes adotam, não raras vezes, atitudes como "Ah, deixa pra lá. Ele não entende mesmo", que acabam por limitar as oportunidades dos alunos de avançarem na sua proficiência em português. Timidez, desinteresse e rebeldia também são algumas características por vezes atribuídas àqueles que não se comportam, em sala de aula, como "deveriam".

Em casos mais extremos, estudantes com baixo rendimento escolar são mesmo patologizados, conforme notícia veiculada pelo Estado de São Paulo (BRANDALISE, 2017). Segundo esse texto, um grande contingente de discentes estrangeiros matriculados nas escolas da cidade de São Paulo tem sido encaminhado a unidades de saúde para avaliação médica e psicológica, numa proporção muito maior quando comparada aos alunos brasileiros. Em uma determinada escola, 18 dos 30 alunos imigrantes matriculados foram encaminhados com suspeita de déficit de aprendizagem e autismo. A menina síria focalizada na notícia estava há quatro meses em São Paulo com sua família, quando recebeu de sua professora um pedido de avaliação psicológica - a

\footnotetext{
${ }^{17}$ A título de ilustração, retomamos aqui um estudo realizado por Leavitt e Stairs (1988) sobre escolas indígenas Isumaq, no Canadá, citado por Maher (2007b). Os autores concluem que, na cultura de aprender nativa, o erro do aprendiz é muito mais crítico do que na cultura escolar formal, em que se tende a encorajar a tentativa e o erro. Ignorando essa diferença, professores não-índios acreditavam que seus alunos indígenas não tinham interesse em aprender, já que se recusavam a atender prontamente a suas solicitações. Os docentes também interpretavam a falta de esforço dos estudantes para verbalizar o conhecimento como evidência de não-aprendizagem, quando, na cultura de aprender desses estudantes, os conceitos e princípios estão implícitos nos relatos de experiências e de histórias - ao invés de serem explicitados por meio de abstrações típicas da cultura escolar ocidental. Ainda de acordo com Leavitt e Stairs (1998) apud Maher (2007b), a cultura desses alunos valoriza muito a interação no grupo, concebendo o conhecimento como um recurso compartilhado adquirido coletivamente, contrariamente às práticas em sala de aula que estimulam o individualismo e a competição, o que produzia certo desconforto entre os discentes.
} 
REVISTA X, Curitiba, volume 13,n.1,p. 87-110, 2018.

\section{Dossiê Especial: Português como Língua Adicional em contextos de minorias:}

(co)construindo sentidos a partir das margens

BIZON \& DINIZ (Orgs.)

suspeita era de dislexia, déficit de atenção e deficiência de aprendizagem. Após um período em que temeu nunca ser capaz de falar e escrever em português, a menina concluiu: "não sou burra, eu só não sei a língua!". Em seguida, deixou a escola, para onde só retornou depois de frequentar, durante um ano, um curso de PLAc em uma ONG. Se a menina síria em questão teve condições subjetivas de recusar o rótulo que lhe foi atribuído na escola, esse não é o caso de muitos alunos significados pelo discurso da falta. Daí a importância de um sistema escolar que - no lugar de se isentar de suas responsabilidades, delegando-as para profissionais do campo da Saúde -, prepare professores e demais profissionais da educação para o trabalho com discentes que não têm o português como língua materna.

\section{CONSIDERAÇÕES FINAIS}

O percurso feito ao longo deste artigo evidencia uma série de políticas de (in)visibilização de estudantes imigrantes e refugiados no Ensino Básico brasileiro, inclusive em documentos que, na superfície, advogam em favor da diversidade linguística. Esse é o caso da BNCC, um instrumento estratégico de política linguística em nível federal, que carece de diretrizes para a valorização de outras línguas no espaço escolar e em seu entorno, o que seria crucial em uma política que se sustente efetivamente em uma perspectiva crítica de multiculturalismo, tal como defendida por Maher (2007a). Como efeito do silenciamento do fato de que milhares de alunos matriculados em nossas escolas de Ensino Básico não têm o português como língua materna, tampouco há diretrizes mínimas para o trabalho com esse público - o que traz especificidades para o ensino-aprendizagem não só de Língua Portuguesa, mas também de todos os demais componentes curriculares.

Vimos que processos de invisibilização de estrangeiros - assim como de brasileiros que não têm o português como língua materna - também marcam as políticas de formação de pedagogos e professores no Brasil, a despeito de algumas iniciativas recentes para a docência de PLAc no Ensino Básico. Entre os efeitos de uma educação linguística restrita, pouco sensível ao multiculturalismo crítico, chamamos a atenção 
REVISTA X, Curitiba, volume 13,n.1,p. 87-110, 2018.

\section{Dossiê Especial: Português como Língua Adicional em contextos de minorias:}

(co)construindo sentidos a partir das margens

BIZON \& DINIZ (Orgs.)

para o funcionamento do discurso da falta na área de PLA, sustentado por uma perspectiva "autômoma" de letramento, na contramão de um modelo "ideológico", tal como defendido por Street $(1984 ; 2013)$. Em casos extremos, tal discurso tem levado à patologização de discentes estrangeiros, trazendo à tona a absoluta fragilidade de políticas para seu recebimento em instituições escolares brasileiras, reveladora da dupla face da crise migratória. Como destacam Bizon e Camargo (2018) a partir de Baeninger e Peres (2015), a crise não está apenas na origem dos movimentos de deslocamento forçado, mas também nas sociedades receptoras, como a brasileira, que se veem despreparadas para acolher imigrantes e refugiados.

À guisa de conclusão, em conformidade com o que propõe a Linguística Aplicada Indisciplinar, salientamos a necessidade de um movimento contínuo de interrogação das certezas que já têm se sedimentado na área de PLAc no Brasil, apesar de sua configuração bastante recente. Colocar em suspensão o próprio termo "Português como Língua de Acolhimento" é um primeiro passo importante nessa direção - ainda que defendamos a importância dessa designação, como gesto político que lança luzes sobre demandas de ensino, pesquisa e extensão que podem intervir na produção e democratização de "mobilidades e multiterritorialidades" (BIZON, 2013, p. 123).

É preciso considerar, pois, que o português não necessariamente é uma língua de acolhimento para imigrantes, refugiados e outros sujeitos pertencentes a grupos minoritarizados. Partir do princípio de que ele sempre o é - ou pode vir a sê-lo a depender da abordagem, método ou técnicas adotados pelo professor - é apagar os conflitos identitários que podem estar em jogo para alguns sujeitos quando passam a (ter que) se relacionar com o português. Para alguns, por exemplo, esse idioma pode ser, acima de tudo, uma "ferramenta de defesa pessoal" (LOPEZ, 2016). Para outros, talvez, a suposta "língua de acolhimento" possa representar "o risco do exílio" (REVUZ, 2006), na contradição com um desejo de ser e estar apenas na língua materna, no lar de onde nunca se imaginou querer sair um dia. Nesse sentido, parece-nos particularmente profícuo o deslocamento proposto por Bizon e Camargo (2018, p. 717), para se pensar não em "língua de acolhimento", mas em "acolhimento em línguas". Processos de desnaturalização dessa natureza são imprescindíveis na área de PLAc - seja no Ensino 
REVISTA X, Curitiba, volume 13,n.1,p. 87-110, 2018.

Dossiê Especial: Português como Língua Adicional em contextos de minorias:

(co)construindo sentidos a partir das margens

BIZON \& DINIZ (Orgs.)

Básico, seja em outros contextos -, a fim de que, a despeito de nossas boas intenções ao procurar garantir o direito de que grupos minoritarizados tenham acesso à língua majoritária do Brasil, não acabemos por reproduzir, sob outras roupagens, práticas assimilacionistas e segregadoras que marcam nossa história.

\section{REFERÊNCIAS}

ALTO COMISSARIADO DAS NAÇÕES UNIDAS PARA OS REFUGIADOS (ACNUR)/ UNITED NATIONS HIGH COMMISSIONER FOR REFUGEES (UNHCR). Global trends: forced displacement in 2015. Switzerland: UNCHR, 2016. Disponível em: <https://s3.amazonaws.com/unhcrsharedmedia/2016/2016-06-20global-trends/2016-06-14-Global-Trends-2015.pdf>. Acesso em: 03 ago. 2018.

BAENINGER, R. A.; PERES, R. G. SOS Português: imigração haitiana em São Paulo. In: Encontro Anual da ANPOCS, 39., 2015, Caxambu, MG. Anais... São Paulo, SP: ANPOCS, 2015.

BARBOSA, L. M. A. Acolhimento e escolarização de imigrantes no ensino básico de Brasília (Distrito Federal): perspectivas e ações. In: FIGUEIREDO, F. J. Q.; SIMÕES, D. (Orgs). Contribuições da Linguística Aplicada para a Educação Básica. Campinas,SP: Pontes, 2018, p. 273-294.

BIZON, A. C. C. Narrando o exame Celpe-Bras e o convênio PEC-G: a construção de territorialidades em tempos de internacionalização. Tese (Doutorado em Linguística Aplicada). Campinas, Universidade Estadual de Campinas, 2013. Disponível em: <http://www.bibliotecadigital.unicamp.br/document/?code=000911713\&opt=4>.

Acesso em: 10 ago. 2018.

BIZON, A. C. C.; CAMARGO, H. R. E. Acolhimento e ensino da língua portuguesa à população oriunda de migração de crise no município de São Paulo: Por uma política do atravessamento entre verticalidades e horizontalidades. In: BAENINGER et al (orgs.). Migrações Sul-Sul. Campinas,SP: NEPO/UNICAMP, 2018, p. 712-726.

BOHEM, C. Imigrantes estão distribuídos pelo interior do Brasil, mostra pesquisa. Agência Brasil, 14 abril 2018. Disponível em: <http://agenciabrasil.ebc.com.br/geral/noticia/2018-04/imigrantes-estao-distribuidospelo-interior-do-brasil-mostra-pesquisa> Acesso em: 26 ago. 2018.

BRANDAliSE, V. H. Autista, não: imigrante. O Estado De São Paulo. São Paulo, 19 mar. 2017. Disponível em:<http://educacao.estadao.com.br/noticias/geral,autista-naoimigrante, 70001705273>. Acesso em: 26 set. 2017. 
REVISTA X, Curitiba, volume 13,n.1,p. 87-110, 2018.

Dossiê Especial: Português como Língua Adicional em contextos de minorias:

(co)construindo sentidos a partir das margens

BIZON \& DINIZ (Orgs.)

BRASIL. Presidência da República. Casa Civil. Subchefia para Assuntos Jurídicos. Lei n. 9.394, de 20 de dezembro de 1996. Disponível em: <http://www.planalto.gov.br/CCIVIL_03/Leis/L9394.htm>. Acesso em: 05 ago. 2018.

Presidência da República. Casa Civil. Subchefia para Assuntos Jurídicos. Lei 11.161, de 5 de agosto de 2005. Disponível em: <http://www.planalto.gov.br /ccivil_03/_ato2004-2006/2005/lei/111161.htm>. Acesso em: 03 ago. 2018.

Presidência da República. Casa Civil. Subchefia para Assuntos Jurídicos.

Decreto n. 7.948, de 12 de março de 2013. Disponível em: <http://www.planalto.gov.br/ccivil_03/_Ato2011-2014/2013/Decreto/D7948.htm>.

Acesso em: 05 ago. 2018.

BRASIL. Ministério da Justiça e Cidadania (MJC). Nota à imprensa: esclarecimento sobre concessão de vistos humanitários aos haitianos. Brasília: 2016. Disponível em: <http://justica.gov.br/noticias/nota-a-imprensa-29>. Acesso em: 10 ago. 2018.

BRASIL. Ministério da Educação. Base Nacional Comum Curricular. Brasília, 2017a. Disponível em:<http://basenacionalcomum.mec.gov.br/wp-content/uploads/ 2018/06/BNCC_EI_EF_110518_versaofinal_site.pdf>. Acesso em: 05 ago. 2018.

Congresso Nacional. Lei . $^{0}$ 13.445, de 24 de maio de 2017, 2017 b. Disponível em: <http://pesquisa.in.gov.br/imprensa/ jsp/ visualiza/index.jsp?jornal= 1\&pagina=1\&data=25/05/2017>. Acesso em: 03 ago. 2018.

Presidência da República. Casa Civil. Subchefia para Assuntos Jurídicos. Lei n. 13.415, de 16 de fevereiro de 2017, 2017c. Disponível em: <http://www.planalto.gov.br/CCIVIL_03/_Ato2015-2018/2017/Lei/L13415.htm\#art2.> Acesso em: 05 ago. 2018.

Ministério da Justiça. Comitê Nacional para os Refugiados / Secretaria Nacional de Justiça. Refúgio em números. $3^{\mathrm{a}}$ edição, 2018a. Disponível em: $<$ http://www.casacivil.gov.br/operacao-acolhida/documentos/refugio-em-numeros-3aedicao-conare-secretaria-nacional-de-justica-ministerio-dajustica/@@download/file/refugio-em-numeros_1104.pdf>. Acesso em: 01 ago. 2018.

BRASIL. Ministério da Justiça. Gabinete do Ministro. Portaria Interministerial No 11 de 03 de maio de 2018, 2018b. Disponível em: <https://www.jusbrasil.com.br/diarios/188991340/dou-secao-1-04-05-2018-pg-46>. Acesso em: 05 ago. 2018.

CAVALCANTI, M. C. Educação linguística na formação de professores de línguas: intercompreensão e práticas translíngues. In: MOITA LOPES, L. P. da. Linguística Aplicada na modernidade recente. São Paulo: Parábola, 2013, p. 211-226. 
REVISTA X, Curitiba, volume 13,n.1,p. 87-110, 2018.

Dossiê Especial: Português como Língua Adicional em contextos de minorias:

(co)construindo sentidos a partir das margens

BIZON \& DINIZ (Orgs.)

CHARLEAUX, J. P. Qual o retrato da migração estrangeira hoje no Brasil, segundo este especialista. Nexo, 2017. Disponível em: <https://www.nexojornal.com.br /entrevista/2017/08/26/Qual-o-retrato-da-migra\%C3\%A7\%C3\%A3o-estrangeira-hojeno-Brasil-segundo-este-especialista> Acesso em: 10 ago. 2018.

CLOCHARD, O. Les réfugiés dans le monde entre protection et illégalité. EchoGéo, v. 2, p.1-9, 2007. Disponível em: 〈http://echogeo.revues.org/1696> Acesso em: 01 ago. 2018.

DINIZ, L. R. A. A formação de professores para o ensino de português como "língua de acolhimento": desnaturalizando alguns discursos. In: Mesa plenária "Experiências de acolhimento", ocorrida no II Encontro de Português como Língua de Acolhimento (ENPLAc). Campo Grande, Universidade Estadual do Mato Grosso do Sul, 2018a.

O ensino de português como língua de acolhimento no Ensino Básico: para início de conversa. In: $1^{\circ}$ encontro presencial do Ciclo de Debates em Português como Língua de Acolhimento no Ensino Básico. Belo Horizonte, Universidade Federal de Minas Gerais, 2018b.

DINIZ, L. R. A.; BIZON, A. C. C. Discursos sobre a relação Brasil/África "lusófona" em políticas linguísticas e de cooperação educacional. Línguas e instrumentos linguísticos, 36, jul. - dez. 2015, p. 125-165. Disponível em: <http://www.revistalinguas.com/edicao36/artigo6.pdf>. Acesso em: 10 ago. 2018.

DINIZ, L. R. A; MIRANDA, Y. C. C. de. O acolhimento linguístico de estudantes na Rede Municipal: uma parceria entre a UFMG e a Secretaria Municipal de Educação. In: Encontro com professores de Língua Inglesa. Belo Horizonte: Secretaria Municipal de educação de Belo Horizonte, 2018.

FUNDO DAS NAÇÕES UNIDAS PARA A INFÂNCIA / UNITED NATIONS CHILDREN'S FUND (UNICEF). Uprooted the growing crisis for refugee and migrant children in 2016, 2016. Disponível em: <http://www.unicef.org/lac/20160907

_UNICEF_Uprooted_Low(1).pdf>. Acesso em: 01 ago. 2018.

INSTITUTO UNIBANCO. Aprendizagem em foco, n. 38. fev. 2018. Disponível em: $<$ http://www.institutounibanco.org.br/aprendizagem-em-foco/38>. Acesso em 05 ago. 2018.

LEAVITT, R.; STAIRS, A. On language teaching as a cultural activity - messages from native education to TESL-Canada. Texto mimeografado inédito, 1988.

LOPEZ, A. P. de A. Subsídios para o planejamento de cursos de português como língua de acolhimento para imigrantes deslocados forçados no Brasil. Dissertação (Mestrado em Linguística Aplicada). Belo Horizonte, Universidade Federal de Minas Gerais, 2016. Disponível em: <http://www.bibliotecadigital.ufmg.br/dspace/bitstream/ 
REVISTA X, Curitiba, volume 13,n.1,p. 87-110, 2018.

Dossiê Especial: Português como Língua Adicional em contextos de minorias:

(co)construindo sentidos a partir das margens

BIZON \& DINIZ (Orgs.)

handle/1843/RMSA-AJTNHQ/disserta_o_poslin_ana_lopez_2016.pdf?sequence=1>. Acesso em: 05 ago. 2018.

\section{LOPEZ, A. P. A.; DINIZ, L. R. A. Iniciativas jurídicas e acadêmicas para o} acolhimento no Brasil de deslocados forçados, no prelo.

MAHER, T. M. A educação do entorno para a interculturalidade e o plurilingüismo. In: KLEIMAN, A. B.; CAVALCANTI, M. C. (orgs.) Lingüística Aplicada: suas faces e interfaces. Campinas, SP: Mercado de Letras, 2007a, p. 255-270.

Do casulo ao movimento: a suspensão das certezas na educação bilíngüe e intercultural. In: CAVALCANTI, M.; BORTONI-RICARDO, S. M. (orgs.). Transculturalidade, linguagem e educação. Campinas, SP: Mercado de Letras, 2007b, p. 67-94.

MINAS GERAIS. Secretaria de Estado de Educação. Currículo Básico Comum do Ensino Fundamental - Língua Portuguesa, 2008. Disponível em: $<$ https://www.trescoracoes.mg.gov.br/docs/seduc/cbc-anos-finais-linguaportuguesa.pdf $>$. Acesso em: 03 ago. 2018.

MOITA LOPES, L. P. (Org.). Uma linguística aplicada mestiça e ideológica: interrogando o campo como linguista aplicado. In: MOITA LOPES, L. P. (Org.) Por uma Linguística Aplicada Indisciplinar. São Paulo: Parábola, 2006, p.13-44.

NEVES, A. O. A política linguística de acolhimento a crianças imigrantes no Ensino Fundamental brasileiro: um estudo de caso. Dissertação (Mestrado em Estudos Linguísticos). Belo Horizonte, Universidade Federal de Minas Gerais, 2018.

OLIVEIRA, G. M. de. Prefácio. In: CALVET, L.-J. As políticas linguísticas. São Paulo: Parábola/IPOL, 2007. p 7-10.

ORLANDI, E. L. P. Espaços linguísticos e seus desafios: convergências e divergências. Rua (Unicamp), v. 18, p. 1-15, 2012.

PARANÁ. Secretaria de Estado da Educação (SEED). Edital de credenciamento n. 44/2017. Curitiba, 26 de julho de 2017.

PENNYCOOK, A. Uma linguística aplicada transgressiva. In: MOITA LOPES, L. P. Por uma Linguística Aplicada Indisciplinar. São Paulo: Parábola, 2006, p. 67-84.

REINOLDES, M.; MANDALÁ, P.; AMADO, R. Portas abertas: português para imigrantes. São Paulo: Prefeitura de São Paulo, 2017. Disponível em: $<$ https://www.prefeitura.sp.gov.br/cidade/secretarias/direitos_humanos/migrantes/progr amas_e_projetos/portas_abertas/index.php?p=259310 >. Acesso em: 06 ago. 2018. 
REVISTA X, Curitiba, volume 13,n.1,p. 87-110, 2018.

Dossiê Especial: Português como Língua Adicional em contextos de minorias:

(co)construindo sentidos a partir das margens

BIZON \& DINIZ (Orgs.)

REVUZ, C. A língua estrangeira entre o desejo de um outro lugar e o risco do exílio. In: SIGNORINI, I. (org.). Língua(gem) e identidade. Elementos para uma discussão no campo aplicado. São Paulo: Mercado de Letras, 2006, p. 213-230.

RUANO, B. P.; OLMO, F. J. C. del; ALMEIDA, M. R. Ações de Política de Formação de Professores em PLE na UFPR. In: SCARAMUCCI, M. V. R.; BIZON, A. C. C. (orgs). Formação inicial e continuada de professores de Português Língua Estrangeira no Brasil. Campinas, SP: Pontes, no prelo.

SANTOS, M. C. "Felicidade Clandestina": refúgio e família no Brasil. Campinas: Dissertação (Mestrado em Demografia). Campinas, Universidade Estadual de Campinas, 2014. Disponível em: <http://www.bibliotecadigital.unicamp.br/document/ ?code $=000936207>$. Acesso em: 01 ago. 2018.

SÃO PAULO. Prefeitura de São Paulo. Ementa do curso Portas Abertas: Português para Imigrantes, 2017a. Disponível em: <http://www.prefeitura.sp.gov.br/cidade/ secretarias/upload/direitos_humanos/MIGRANTES/PORTAS_ABERTAS/Ementa\%20 do\%20Portas\%20Abertas\%20Portugues\%20para\%20Imigrantes.pdf $>$. Acesso em: 05 ago. 2018.

Secretaria Municipal de Direitos Humanos e Cidadania (SMDHC) e Secretaria Municipal de Educação (SME). Portaria Intersecretarial SMDHC/SME n. 002, de 18 de agosto de 2017 e Portaria Intersecretarial SMDHC/SME n. 002, de 19 de dezembro de 2017, 2017b. Disponível em: <http://www.prefeitura.sp.gov.br/cidade/ secretarias/upload/direitos_humanos/MIGRANTES/PORTAS_ABERTAS/PORTARIA \%20INTERSECRETARIAL\%20SMDHC-SME.PDF>. Acesso em: 05 ago. 2018.

STREET, B. V. Literacy in theory and practice. Cambridge: Cambridge University Press, 1984.

Políticas e práticas de letramento na Inglaterra: uma perspectiva de letramentos sociais como base para uma comparação com o Brasil. Cad. Cedes, Campinas, v. 33, n. 89, p. 51-71, jan.-abr. 2013. Disponível em: <https://www.researchgate.net/profile/ Brian_Street/publication/262647294_Policies_and_practices_of_literacy_in_England_a _social_literacies_perspective_as_a_basis_for_comparison_with_Brazil/links/544e40b8 0cf29473161aa081/Policies-and-practices-of-literacy-in-England-a-social-literaciesperspective-as-a-basis-for-comparison-with-Brazil.pdf> . Acesso em: 10 ago. 2018. 